\title{
Crystal and molecular structure of hexagonal form of lipase B from Candida antarctica
}

\author{
Paweł Strzelczyk’1, Grzegorz D. Bujacz'1, Piotr Kiełbasiński² and Jarosław Błaszczyk ${ }^{2 \varpi}$ \\ ${ }^{1}$ Lodz University of Technology, Institute of Technical Biochemistry, Łódź, Poland; ${ }^{2}$ Centre of Molecular and Macromolecular Studies, Polish \\ Academy of Sciences, Department of Heteroorganic Chemistry, Łódź, Poland
}

\begin{abstract}
During crystallization screenings of commercially available hydrolytic enzymes, the new, hexagonal crystal form of CAL-B, has been discovered and hereby reported. The NAG molecules, which were closing the glycosylation site in the orthorhombic form, in hexagonal structure make the glycosylation site open. It is unknown whether the opening and closing of the glycosylation site by the 'lid' NAG molecules, could be related to the opening and closing of the active center of the enzyme upon substrate binding and product release.
\end{abstract}

Key words: CAL-B, lipase B, Candida antarctica, apo form, crystallographic polymorphism, macromolecular crystallography

Received: 21May, 2015; revised: 07 October, 2015; accepted: 18 November, 2015; available on-line: 30 December, 2015

\section{INTRODUCTION}

Lipases (EC 3.1.1.3) catalyze the hydrolysis of carboxylic acid esters in aqueous media but also the esterification or transesterification in organic solvents (Bornscheuer \& Kazlauskas, 1999; Paravidino et al., 2012; Singh et al., 2012). The studies on applying commercially available hydrolytic enzymes, including lipase B from Candida antarctica (CAL-B), Candida rugosa lipase (CRL), lipase PS Amano, AK Amano, AH Amano or lipoprotein lipase (LPL), to the synthesis of chiral non-racemic heteroorganic compounds, have been carried out in our Department for many years (Kaczmarczyk et al., 2011; Kiełbasiński et al., 2003; Kiełbasiński \& Mikołajczyk, 2007; Krasiński et al., 2012; Kwiatkowska et al., 2011; Rachwalski et al., 2008). We have decided to make theoretical (Krasiński et al., 2012) and experimental attempts to explain the catalytic mechanism of the enzymes and the nature of their promiscuous behavior.

There is only limited information in literature regarding the crystal structure and active site architecture of these enzymes. In the Protein Data Bank (PDB), there are 12 structures available for lipase B from Candida antarctica (CAL-B): 1TCA, 1TCB and 1TCC (Uppenberg et al., 1994), 1LBS and 1LBT (Uppenberg et al., 1995), 3ICV and 3ICW (Qian et al., 2009), 4K5Q, 4K6G, $4 \mathrm{~K} 6 \mathrm{H}$, and 4K6K (Xie et al., 2014), and 3W9B (Kim et al., 2014). For Candida rugosa lipase (CRL), there are 9 structures: 1CRL (Grochulski et al., 1993), 1GZ7 (Mancheno et al., 2003), 1LPM and 1LPS (Cygler et al., 1994), 1LPN, 1LPO, and 1LPP (Grochulski et al., 1994a), 1TRH (Grochulski et al., 1994b), and 3RAR (Colton et al., 2011). For lipase PS Amano, there is one PDB entry, 1OIL (Kim et al., 1997). For lipases $A K$ Amano, $A H$
Amano, and lipoprotein lipase (LPL), there are no X-ray crystal structures reported to date.

All above mentioned structures are insufficient to explain the mechanism of action of these enzymes towards the heteroorganic substrates and their analogs which we use in enzyme-controlled chemical reactions conducted in our laboratory (Kaczmarczyk et al., 2011; Kwiatkowska et al., 2011; Krasiński et al., 2012). For that reason, the crystal structures of the enzymes in the appropriate complex forms, i.e., with the particular substrates or analogs that we use, are needed. We hope that our results will shed more light not only on the catalytic mechanism of these enzymes, but also will explain the nature of the enzymes promiscuous behavior.

Among commercially available lipases, which are nowadays expressed in large quantities, lipase B from Candida antarctica (CAL-B) is one of the most extensively used biocatalysts, both in the research and in the industry (Kirk \& Christensen, 2002; Wu et al., 2013). CAL-B belongs to the $\alpha / \beta$-hydrolase family and follows the same reaction mechanism as the other serine hydrolases (Bornscheuer \& Kazlauskas, 1999; Paravidino et al., 2012; Singh et al., 2012). This enzyme is highly stereoselective in a wide variety of chemical transformations. A broad range of CAL-B applications includes kinetic resolution of racemic alcohols and amines or desymmetrization of diols and diacetates (Alatorre-Santamaria et al., 2011; Deska et al., 2010; Frykman et al., 1993; Kaczmarczyk et al., 2011; Kiełbasiński et al., 2003; Ko et al., 2007; Patterson \& Miller, 2010; Rachwalski et al., 2008; Santaniello et al., 2006; Waagen et al., 1993). Numerous examples pertain to the stereoselective synthesis of chiral intermediates for the production of various pharmaceuticals and plant-protecting agents (Andualema \& Gessesse, 2012; Baldessari, 2012; Naik et al., 2010; Sharma et al., 2011; Song et al., 2008). Moreover, there are many cases of promiscuous reactions catalyzed by $\mathrm{CAL}-\mathrm{B}$, including aldol reactions, Michael additions, vinyl polymerization, and even oxidations (Branneby et al., 2004; Carboni-Oerlemans et al., 2006; Carlqvist et al., 2003; Carlqvist et al., 2005; Hult \& Berglund, 2007; Madalińska et al., 2012; Rustoy et al., 2007; Sharma et al., 2009; Svedendahl et al., 2005; Wu et al., 2010).

Structurally, lipase B from Candida antarctica (CAL-B) is a macromolecule with molecular mass of about $33 \mathrm{kDa}$ and 317 amino acid residues in its polypeptide chain.

e-mail: blaszcz8@cbmm.lodz.pl

PDB accession numbers: 4ZV7, Crystal structure of hexagonal form of lipase B from Candida antarctica

Abbreviations: CAL-B, Lipase B from Candida antarctica; NAG, Nacetyl-D-glucosamine; RMSD, Root-Mean-Square deviations; PDB, the Protein Data Bank 
The active site is composed of a catalytic triad Ser-HisAsp, an oxyanion hole that stabilizes the transition state of the reaction, and a binding pocket consisting of two compartments, one for the acyl moiety of the ester and another one for the alcohol part (Otto et al., 2000; Uppenberg et al., 1994; Uppenberg et al., 1995).

In order to improve thermostability, activity, stereoselectivity, and expression rate of CAL-B and to tailor it for different applications, a range of mutants have been developed, with main focus on kinetic resolution of chiral alcohols (Wu et al., 2013; for details, see references 14-17 in that paper). For improvement of extracellular production of CAL-B enzyme in Escherichia coli and improvement of the enzyme stability, an anion tag has been added, and the structurally flexible residues within the active site were mutated. The X-ray crystal structures of CAL-B, with such sequence modifications, were determined (PDB entries 3W9B (Kim et al., 2014), and $4 \mathrm{~K} 6 \mathrm{G}, 4 \mathrm{~K} 6 \mathrm{H}, 4 \mathrm{~K} 6 \mathrm{~K}, 4 \mathrm{~K} 5 \mathrm{Q}$ (Xie et al., 2014)). Since the truncated loop variant, cp283 $\Delta 7$, showed substantial increase in the catalytic activity of the enzyme, the two crystal structures of that variant, in the apo form and with a bound inhibitor (PDB entries $3 \mathrm{ICV}$ and $3 \mathrm{ICW}$, respectively), were determined (Qian et al., 2009).

Of particular concern, in one of our ongoing research projects, is the kinetic resolution of racemic P-stereogenic alkoxy(hydroxymethyl)phenylphosphine oxides and P-stereogenic alkoxy(hydroxymethyl)phenylphosphine P-boranes via their enzymatic acetylation (Kwiatkowska et al., 2011). Recently, we reported the results of molecular modeling of the hydrolysis reactions of acetoxymethyl(ipropoxy)-phenylphosphine oxide and its P-borane analogue, acetoxymethyl(i-propoxy)-phenylphosphine P-borane, promoted by the CAL-B enzyme (Krasiński et al., 2012). These theoretical calculations suggested a hypothetical explanation of the stereochemistry of the observed hydrolysis reactions. At present, our goal is to confirm our theoretical results experimentally, by crystallization and X-ray crystal structure determination of the CAL-B enzyme in the form of a complex with the above mentioned heteroorganic ligands and their analogs.

In this work, we would like to present our first result of long-term crystallization screenings of commercially available enzyme candidates. While working on the crystallization screening of a newly purchased, crystallization grade sample of CAL-B enzyme, we discovered a new, hexagonal crystal form of this enzyme. This new form is hereby described in this paper. Due to high symmetry and good diffraction properties, the crystals of this form may by useful in obtaining complexes with various ligands.

\section{MATERIALS AND METHODS}

Protein purchase and screening. Lipase B from Candida antartica (CAL-B) was purchased from Hampton Research (Aliso Viejo, CA, USA, Cat No. HR7-099). As declared by the manufacturer, it was a high quality, crystallization grade sample produced by submerged fermentation of a genetically modified Aspergillus oryzae microorganism. Prior to crystallization, the purchased sample has been subjected in our lab to final purification using size exclusion chromatography which was performed on an XK 16/60 column (Amersham Biosciences, Uppsala, Sweden) filled with Superdex $75 \mathrm{pg}$, where a mixture of $100 \mathrm{mM} \mathrm{NaCl}$ and $10 \mathrm{mM}$ Tris $(\mathrm{pH} 7.3)$ was used as a buffer. The crystallization screening involved the use of the conditions provided by the protein manufacturer and also the use of the set of 50 unique solutions commercially available from Hampton Research Crystal Screen One (Aliso Viejo, CA, USA, Cat No. HR2-110). To our surprise, none of these conditions resulted in crystals of suitable quality. Therefore, we needed to explore new crystallization conditions.

Crystallization. Lipase B from Candida antarctica was crystallized using the vapour diffusion technique in hanging drops. We finally obtained two crystal forms: monoclinic and hexagonal. Both forms were obtained from different crystallization conditions. Monoclinic crystals grew from $22 \%$ (w/v) polyethylene glycol 4000 , $0.05 \mathrm{M}$ sodium acetate $(\mathrm{pH} 3.6), 10 \%$ isopropanol with addition of $5 \%(\mathrm{w} / \mathrm{v}) \mathrm{n}$-octyl- $\beta$-D-glucoside. The monoclinic $\left(\mathrm{P} 2_{1}\right)$ form is already known and reported in the literature as PDB entry 1TCB (Uppenberg et al., 1994). The hexagonal $\left(\mathrm{P}_{3} 22\right)$ form is new (This work). The hexagonal crystals have been obtained at room temperature $\left(21^{\circ} \mathrm{C}\right)$ from $24 \%(\mathrm{w} / \mathrm{v})$ polyethylene glycol 3350, $0.1 \mathrm{M}$ citric acid, and $0.1 \mathrm{M}$ sodium acetate $(\mathrm{pH} 5.5)$, by mixing equal volumes of protein $(10 \mathrm{mg} / \mathrm{ml}$ protein in ultrapure water) and well solutions. The crystals appeared after 14 days and grew within a few additional days.

Data collection and processing. X-ray diffraction data for Lipase B from Candida antarctica were collected at $100 \mathrm{~K}$ using a SuperNova diffractometer (Agilent Technologies) equipped with a microfocus $\mathrm{CuK} \alpha$ $(1.54 \AA)$ radiation source $(0.8 \mathrm{~mA}$ and $50 \mathrm{kV})$ and a $160 \mathrm{~mm}$ Titan CCD detector. A solution, consisting of $50 \%$ polyethylene glycol 400 mixed with the reservoir solution (in a 1:1 ratio), was used as the cryoprotectant. Before cryocooling, the crystal was transferred into the cryoprotectant solution for a few seconds. The data were processed using CrysAlis ${ }^{\text {Pro }}$ (Agilent Technologies) and merged using Aimless program of the CCP4 package (Evans \& Murshudov, 2013; Winn et al., 2011). Diffraction data were processed up to $2.0 \AA$ resolution. The crystal is hexagonal, space group $\mathrm{PG}_{3} 22$, and the unit cell parameters are: $a=b=89.03 \AA$, and $c=137.26 \AA$. Data collection and refinement statistics are summarized in Table 1 .

Structure solution and refinement. The crystal structure of the hexagonal form of Lipase B from Candida antarctica was solved by the molecular replacement method using Phaser (McCoy, 2007; Winn et al., 2011). The CAL-B structure (PDB 3W9B) (Kim et al., 2014) has been used as the starting model. The model was rebuilt using Fourier maps calculated by Coot (Emsley et al., 2010) and refined using REFMAC5 (Murshudov et al., 2011). Data collection and refinement statistics are summarized in Table 1 . The electron density along the entire protein chain was well defined, and allowed to determine the position of all 317 residues of the entire protein sequence without any ambiguity. Water molecules and alternative conformers for some residues were added manually. Average B-factors were calculated using B-AVERAGE (Murshudov et al., 2011). The structure was validated (Laskowski et al.,1993) and deposited in the Protein Data Bank as entry 4ZV7.

\section{RESULTS AND DISCUSSION}

\section{New crystal form of the CAL-B lipase}

While working with crystallization screening of a newly purchased (from Hampton Research Corp., Aliso Viejo, CA, USA) crystallization grade sample of lipase $\mathrm{B}$ from Candida antarctica (CAL-B), we discovered a new 
Table 1. Data collection and refinement statistics for the hexagonal form of Lipase B from Candida antarctica.

\begin{tabular}{ll}
\hline PDB ID & 4ZV7 \\
\hline Crystal system & Hexagonal \\
\hline Space group & $\mathrm{P}_{3} 22$ \\
\hline Unit cell constants $a, b, c(\AA)$ & $89.03,89.03,137.26$ \\
No. of molecules in asymmetric unit & 1 \\
\hline Solvent content $(\%)$ & 48.2 \\
\hline
\end{tabular}

X-ray data collection

\begin{tabular}{ll}
\hline Wavelength $(\AA)$ & 1.54 \\
\hline Temperature $(\mathrm{K})$ & 100 \\
\hline Resolution range $(\AA)$ & $77.11-2.00$ \\
\hline Completeness (overall/last shell, \%) & $98.1 / 91.1$ \\
\hline Redundancy (overall/last shell) & $8.8 / 2.9$ \\
\hline I/sigma (overall/last shell) & $24.6 / 3.3$ \\
\hline Unique reflections (overall/last shell) & $22034 / 2534$ \\
\hline R (merge) (overall/last shell) & $0.093 / 0.2611$ \\
\hline
\end{tabular}

\section{Refinement}

\begin{tabular}{lc}
\hline$R$ (work) & $0.144^{2}$ \\
\hline$R$ (free) & $0.193^{2}$ \\
\hline No. of protein atoms & 2324 \\
\hline No. of NAG atoms & 28 \\
Bond lengths RMSD $(\AA)$ & 0.02 \\
\hline Bond angles RMSD (o) & 2.0 \\
\hline Average $B$, entire chain $\left(\AA^{2}\right)$ & 23.8 \\
\hline Average $B$, main chain $\left(\AA^{2}\right)$ & 21.3 \\
\hline Average $B$, NAG moiety $\left(\AA^{2}\right)$ & 46.8 \\
\hline
\end{tabular}

Ramachandran plot statistics:

\begin{tabular}{ll}
\hline favoured regions (\%) & 97.0 \\
\hline allowed regions (\%) & 3.0 \\
\hline outliers (\%) & 0.0 \\
\hline
\end{tabular}

${ }^{1} R($ merge $)=\Sigma_{h} \Sigma_{j}\left|I_{h j}-\left\langle I_{h}\right\rangle\right| / \Sigma_{h} \Sigma_{j} I_{h j}$, where $I_{h j}$ is the intensity of observation $j$ of reflection $h .{ }^{2} R$ (work) $=\Sigma_{h}|| F_{o}|-| F_{c}|| / \Sigma_{h}\left|F_{o}\right|$ for all reflections, where $F_{o}$ and $F_{c}$ are observed and calculated structure factors, respectively. $R_{\text {free }}$ is calculated analogously for the test reflections, randomly selected and excluded from the refinement.

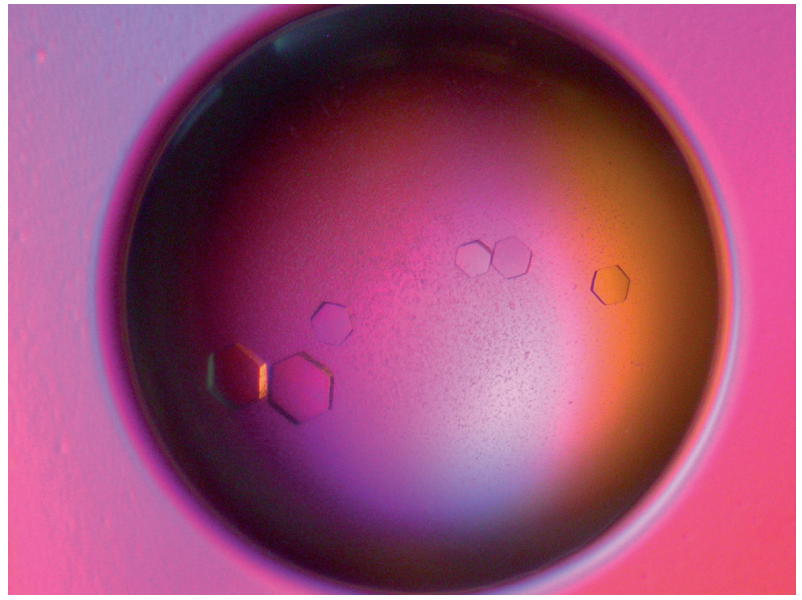

Figure 1. The crystals of the newly obtained hexagonal form of CAL-B.

crystal form of this enzyme. This new form is hereby described in this paper. The crystals of this new form are shown in Fig. 1.

The structures of lipase CAL-B, which have been reported in literature and are available in the Protein Data Bank (PDB) to date, are listed in Table 2. As is seen in Table 2, only structures 1TCA, 1TCB and 1TCC (Uppenberg et al., 1994) are directly related to our newly obtained hexagonal form, 4ZV7. All four structures are of the wild-type enzyme and do not contain a ligand in the active center. Therefore, the further structural comparison and discussion will be limited to these four (4ZV7, 1TCA, 1TCB and 1TCC) structures.

\section{Description of the hexagonal crystal form of CAL-B}

The new crystal form of CAL-B (4ZV7) is hexagonal, and the space group is $\mathrm{P}_{3} 22$ (see Table 1). A single protein monomer is present in the asymmetric unit. The structure contains all 317 residues of the protein sequence, two NAG (N-acetyl-D-glucosamine) molecules, and 331 water molecules. All protein residues are very well visible in electron density, without any ambiguity. Four residues: Ser28, Thr159, Arg242 and Arg309, have two different conformations of their side-chains. There are two cis-peptide bonds present in the structure: one between Pro69 and Pro70 and the second between Gln191 and Pro192. The conformation of the molecule is stabilized by the presence of three disulfide bridges: Cys22-Cys64, Cys216-Cys258, and Cys293-Cys311. The presence and connectivity of these disulfide bridges, align well with those structural elements present in the orthorhombic and monoclinic forms (PDB entries 1TCA and 1TCB) (Uppenberg et al., 1994).

\section{Orthorhombic versus hexagonal form: similarities and differences}

Both orthorhombic and hexagonal forms crystallize with the presence of single protein monomers in the respective asymmetric units. The fold of the CAL-B molecule in the hexagonal form resembles well the fold in the orthorhombic form 1TCA, with identical connectivities of the central $\beta$-sheet, and the same, right-handed, $\beta-\alpha-\beta$ structural motif (Uppenberg et al., 1994). The entire $\mathrm{C} \alpha$ backbones of hexagonal (4ZV7) and orthorhombic (1TCA) forms align with the RMSD value of only $0.66 \AA$. 
Table 2. The crystal structures of CAL-B lipase determined to date.

\begin{tabular}{|c|c|c|c|c|c|c|c|}
\hline PDB code & Crystal system & Space group & $\begin{array}{l}\text { Number of mo- } \\
\text { lecules in asym- } \\
\text { metric unit }\end{array}$ & $\begin{array}{l}\text { Number of re- } \\
\text { sidues in single } \\
\text { chain }\end{array}$ & Resolution $(\AA ̊)$ & $\begin{array}{l}\text { Ligand present } \\
\text { in active site }\end{array}$ & Reference \\
\hline 4ZV7 & Hexagonal & $\mathrm{P}_{3} 22$ & 1 & $317^{a}$ & 2.00 & apo form & (This work) \\
\hline $1 \mathrm{TCA}$ & Orthorhombic & $\mathrm{P} 22_{1} 2_{1} \mathrm{z}_{1}$ & 1 & $317^{a}$ & 1.55 & apo form & $\begin{array}{l}\text { (Uppenberg et al., } \\
\text { 1994) }\end{array}$ \\
\hline $1 \mathrm{TCB}$ & Monoclinic & $\mathrm{P} 2_{1}$ & 2 & $317^{a}$ & 2.10 & apo form & $\begin{array}{l}\text { (Uppenberg et al., } \\
\text { 1994) }\end{array}$ \\
\hline $1 \mathrm{TCC}$ & Monoclinic & $\mathrm{P} 2_{1}$ & 2 & $317^{a}$ & 2.50 & apo form & $\begin{array}{l}\text { (Uppenberg et al., } \\
\text { 1994) }\end{array}$ \\
\hline $1 \mathrm{LBS}$ & Monoclinic & $\mathrm{C} 2$ & 6 & $317^{a}$ & 2.60 & HEE & $\begin{array}{l}\text { (Uppenberg et al., } \\
\text { 1995) }\end{array}$ \\
\hline 1LBT & Monoclinic & $\mathrm{P} 2_{1}$ & 2 & $317^{a}$ & 2.50 & $\mathrm{~T} 80^{f}$ & $\begin{array}{l}\text { (Uppenberg et al., } \\
\text { 1995) }\end{array}$ \\
\hline 3ICV & Trigonal & $\mathrm{P} 3_{2} 21$ & 1 & $316^{b}$ & 1.49 & BTBg & (Qian et al., 2009) \\
\hline $3 I C W$ & Trigonal & $\mathrm{P}_{2} 21$ & 1 & $316^{b}$ & 1.69 & $\mathrm{MHH}^{\mathrm{h}}$ & (Qian et al., 2009) \\
\hline $3 W 9 B$ & Hexagonal & $\mathrm{P}_{5}$ & 4 & $328^{c}$ & 2.90 & apo form & (Kim et al., 2014) \\
\hline $4 \mathrm{~K} 5 \mathrm{Q}$ & Orthorhombic & $\mathrm{C} 222_{1}$ & 1 & $325^{d}$ & 1.49 & apo form & (Xie et al., 2014) \\
\hline $4 \mathrm{~K} 6 \mathrm{H}$ & Monoclinic & $\mathrm{P} 2_{1}$ & 2 & $326^{d}$ & 1.60 & apo form & (Xie et al., 2014) \\
\hline $4 \mathrm{~K} 6 \mathrm{~K}$ & Orthorhombic & $\mathrm{P} 22_{1} 2_{1} 2_{1}$ & 2 & $326^{d}$ & 1.60 & apo form & (Xie et al., 2014) \\
\hline $4 K 6 \mathrm{G}$ & Monoclinic & $\mathrm{P} 2_{1}$ & 2 & $327 c$ & 1.50 & apo form & (Xie et al., 2014) \\
\hline
\end{tabular}

awild-type form; ${ }^{b}$ deletion mutant; 'sequence variant with anion tag; dsequence variant with anion tag and mutations; eHEE, the abbreviation for N-hexylphosphonate ethyl ester in Protein Data Bank Ligand Database; T 80, methylpenta(oxyethyl) heptadecanoate; 9BTB, 2[bis-(2-hydroxy-ethyl)amino]2-hydroxymethyl-propane-1,3-diol; ${ }^{\mathrm{M}} \mathrm{MHH}$, hexyl-methoxy-phosphinic acid

The number of multiple conformations of the side chains is different in both forms. In the orthorhombic form (1TCA) the side chains, for which two conformations were found, are: Ser26, Ile87, and Leu144 (Uppenberg et al., 1994).

The hexagonal form of CAL-B was crystallized in the absence of any (in particular heteroorganic) ligands. The active center of the enzyme, which involves the presence of the catalytic triad residues, Ser105, Asp187, and His224, is open, and only water molecules (eight waters: 906, 961, 1089, 1178, 1200, $1211,1218,1230)$ are found tightly buried there. Therefore, our hexagonal structure is a ligand-free (apo) form of the enzyme (see Table 2).

Interestingly, there are more water molecules in the active center in our hexagonal structure than in the orthorhombic form, where only four water molecules were found (Uppenberg et al., 1994). The catalytic triad residues Ser105, Asp187, and His224, in the active site in the orthorhombic form, 1TCA, have almost identical position and conformation, except for the $\mathrm{C} \beta-\mathrm{O} \gamma$ bond of Ser105, which rotates slightly away from the $\mathrm{N} \varepsilon_{2}$ atom of His224. The movement of the $\mathrm{O} \gamma$ atom of Ser105 is about $0.5 \AA$.
The protein side chains in the hexagonal form of the enzyme are thermally quite stable. The difference between average mobilities of the entire chain $\left(B=23.8 \AA^{2}\right)$ and of the main chain atoms $\left(B=21.3 \AA^{2}\right)$ is very small (Table 1). Interestingly, in contrast to the orthorhombic form, where the increased mobility was observed for the side chains of the catalytic triad residues Ser105-Asp187His224, and where this phenomenon has been suggested to be of functional interest (Uppenberg et al., 1994), our hexagonal form does not show any sign of such mobility increase.

\section{Unexpected opening of the glycosylation site in hexagonal CAL-B. Is this opening functionally related?}

In both orthorhombic (1TCA) and hexagonal (4ZV7) forms, the NAG molecules are present in the glycosylation site and bound to the side chain $\mathrm{N}_{2}$ atom of the Asn74 residue (Fig. 2). However, the positions of these NAG molecules do not align with each other (Fig. 3). In the hexagonal form, the side chain of Asn74 and two visible bound NAG molecules rotate straight out of the protein molecule towards the solvent region. In the orthorhombic form, this side chain and two NAG 


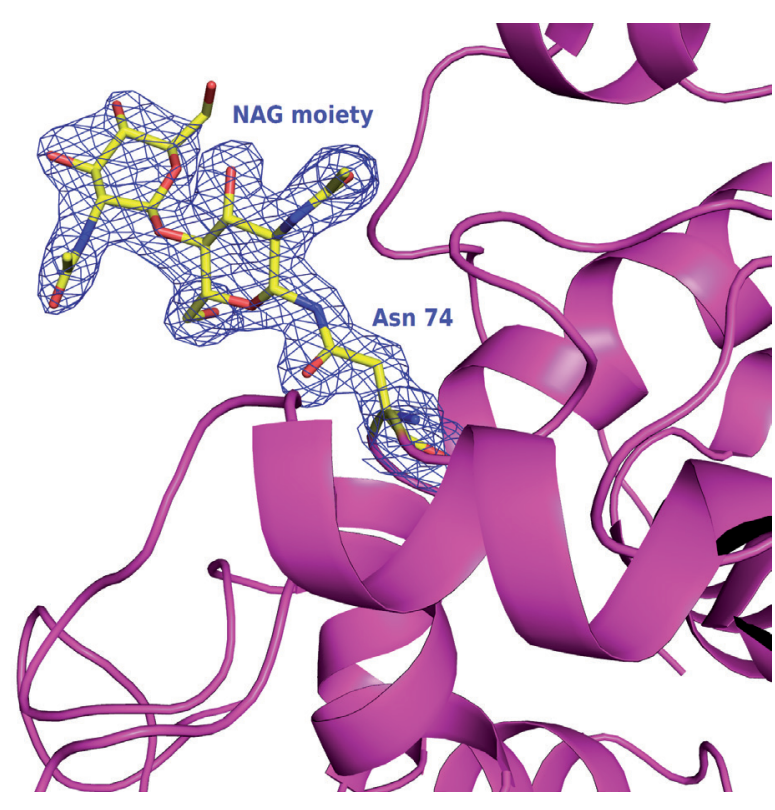

Figure 2. View of the glycosylation site, and the omit map for the NAG moiety and residue Asn74, in the hexagonal form of CAL-B.

The NAG moiety, and residue Asn74 to which it is bound, are shown as stick models in the atomic color scheme (nitrogen in blue and oxygen in red). The electron density for these elements is shown as a blue net.

molecules rotate towards the enzyme molecule, and close the glycosylation site (Fig. 3). The torsion angle $\mathrm{N}-\mathrm{C} \alpha-$ $C \beta-C \gamma$ of Asn74, which describes this rotation, in the orthorhombic form is $-163^{\circ}$, but in the hexagonal form this angle is $-96^{\circ}$, and resulting in a difference of about 70 degrees.

There are significant differences in interactions, between NAG moiety and the protein, in both forms. In orthorhombic form (1TCA), the first NAG molecule in the chain (the one bound to Asn74) has an extended system of contacts with the protein. There are two direct contacts to the side chains: (NAG1) O3 - $3.22 \AA-$ (Gln11) NE2; and (NAG1) O6 - $2.75 \AA-($ Asp75) OD2. Additionally, four contacts of NAG1 are to protein side chains via water molecules: (NAG1) O6 - 2.69 $\AA-($ Wat515) - $2.96 \AA-$ (Ser10) OG; (NAG1) O7 $-2.64 \AA-($ Wat436) - $2.82 \AA-(\mathrm{Gln} 11) \mathrm{OE} 1$; (NAG1) $07-2.64 \AA-(W a t 436)-2.76 \AA-$ (Tyr82) OH and (NAG1) O7 - $2.74 \AA-$ (Wat567) - $3.25 \AA-$ (Asn79) OD1. The side chain of Asn74, to which the NAG chain is bound, also has one water molecule involved: (Asn74) OD1 - $2.84 \AA$ - (Wat492). The second NAG molecule in the chain is not involved in any intramolecular contacts with the protein in the orthorhombic form. It is involved only in intermolecular contacts, mainly with solvent molecules. The shortest intermolecular distance of NAG2 to the protein side chain of symmetry-related molecule is: (NAG2) O7 - $4.23 \AA$ - (Arg238) NH1. In the hexagonal form (4ZV7), the contacts of NAG1 molecule are: (NAG1) O6 - 2.77 $\AA-($ Wat1015) - $2.85 \AA-($ Wat953) - $2.63 \AA-$ (Asp75) OD2; (NAG1) O7 - $2.65 \AA-$ (Wat958) $2.56 \AA-$ (Wat1102) and (NAG1) O7 - $2.65 \AA-$ (Wat958) - $2.79 \AA-($ Wat907) - $2.39 \AA-($ Tyr82) $\mathrm{OH}$. The Asn74 residue, to which the NAG chain is bound, has similarly a contact with water molecule: (Asn74) OD1 - $2.81 \AA-$ (Wat1038), but this water is

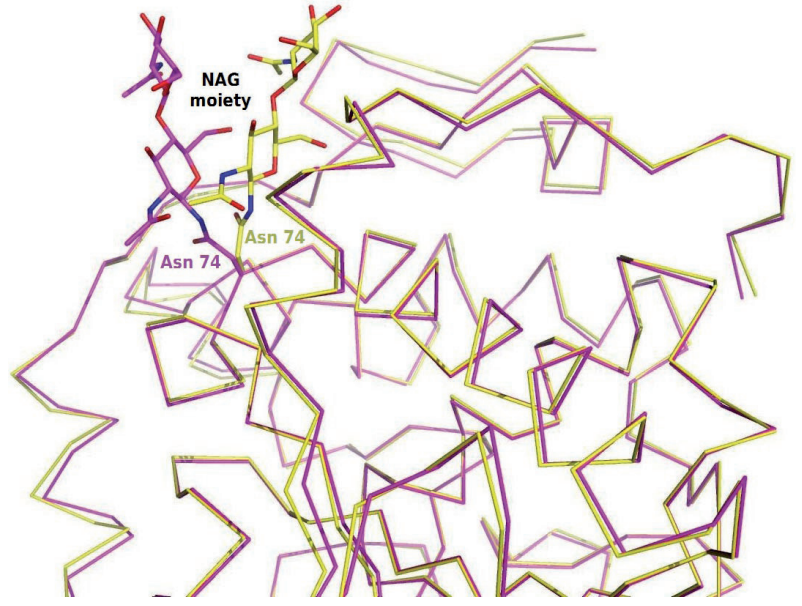

Figure 3. Alignment of the $\mathrm{Ca}$ backbones near the glycosylation sites of the orthorhombic (1TCA, in yellow) and the hexagonal (4ZV7, in magenta) forms of CAL-B.

The alignment reveals opening (4ZV7) and closing (1TCA) of the glycosylation site, by the 'lid' NAG moiety, bound to the side chain $\mathrm{N}_{2}$ atom of Asn74 residue.

located in different place, i.e., does not superimpose with respective water from orthorhombic structure. More, the side chain of residue Asp75, which is next to Asn74, in hexagonal form has its side chain rotated out of the NAG chain. The respective average B-factors for NAG2 and NAG1 are 61.9 $\AA^{2}$ and $31.6 \AA^{2}$. Similar mobility difference between the first and the second NAG molecule in the chain has been observed in the orthorhombic form.

The electron density for the NAG moiety is well defined and highly comparable to the density of the side chain of residue Asn74, to which the NAG moiety is bound (Fig. 2). In the hexagonal form, the entire NAG moiety has increased mobility, in comparison with the protein chain. For example, the avarage value of the B-factor for the NAG moiety is $46.8 \AA^{2}$ (see Table 1), whereas the average B-factor for residue Asn74 is 19.7 $\AA^{2}$. Similar mobility increase was observed for the NAG moiety in the orthorhombic form, where the average B-factor values were $27.7 \AA^{2}$ and $8.7 \AA^{2}$, for the NAG moiety and residue Asn74, respectively.

Such a significant opening of the glycosylation site in the hexagonal form, when compared to a partial closing of this site in the orthorhombic form, is probably the reason that the two regions: first, which involves residues 266-287, and second, which involves C-terminal residues 306-317, do not superimpose well.

We do not know whether the opening (in the hexagonal form) and closing (in the orthorhombic form) of the glycosylation site, by the 'lid' NAG molecules, is just an effect of the crystal packing, or it could be related to the opening and closing of the enzyme active center upon substrate binding and product release.

\section{Conserved, tightly buried water, in all crystal forms}

Of special interest (Uppenberg et al., 1994) is the water molecule (Water number 950 in hexagonal form) which is bound to the $\mathrm{O} \delta_{2}$ atom of the active site residue Asp187 (distance $2.63 \AA$ in hexagonal form) and to the $\mathrm{O} \gamma$ atom of Ser227 residue (distance $3.12 \AA$ in hexagonal form). This water, in the orthorhombic form 1TCA, is located in the same place and has the same 
connection system. While the distance of this water to Asp187 is similar (2.67 $\AA$ ), the connection with Ser227 in the orthorhombic form is much tighter $(2.87 \AA)$. The connectivity of this water molecule in the monoclinic form 1TCB resembles well the situation in the orthorhombic structure. The respective distances of this water are: $2.88 \AA$ (to Asp187) and $2.80 \AA$ (to Ser227) in monomer 1TCB-A, and, respectively, $2.72 \AA$ and $3.01 \AA$, in monomer 1TCB-B.

\section{Structural comparison of hexagonal, orthorhombic and monoclinic forms}

The protein molecule of the orthorhombic form (1TCA) alignes very well with the two independent protein molecules $\mathrm{A}$ and $\mathrm{B}$ of the monoclinic form (1TCB), including not only a good alignment of $\mathrm{C} \alpha$ backbones, but also the alignment of the two NAG molecules that are visible in the glycosylation site of molecule A of the monoclinic form (Uppenberg et al., 1994). The RMSD value of alignment of 1 TCA to 1 TCB-A is $0.53 \AA$, and the RMSD value of alignment of 1TCA to 1 TCB-B is $0.52 \AA$. The RMSD values, for alignment of $4 \mathrm{ZV} 7$ to $1 \mathrm{TCB}-\mathrm{A}$, and for alignment of $4 Z \mathrm{ZV} 7$ to $1 \mathrm{TCB}-\mathrm{B}$, are both equal to $0.64 \AA$.

Since the orthorhombic (1TCA) and monoclinic (1TCB) forms align well, the differences, which were discussed for the $\mathrm{C} \alpha$ backbone conformation and the position of the NAG molecules bound to the side chain of Asn74 in the hexagonal (4ZV7) and the orthorhombic (1TCA) forms, apply to the same extent to the comparison of the hexagonal form $(4 \mathrm{ZV} 7)$ with the monoclinic form (1TCB) (Uppenberg et al., 1994).

The striking difference between the three crystal forms: monoclinic (1TCB and 1TCC), orthorhombic (1TCA) and hexagonal (4ZV7), is obviously the packing of the protein molecules in the crystals, and the number of molecules that are present in the asymmetric units. In monoclinic forms 1TCB and 1TCC, the two molecules are present in the asymmetric units. These two independent monomers, 1TCB-A and 1TCB-B, are packed in such way that the large hydrophobic surface around the active site pocket of one molecule packs against the corresponding surface of the other molecule (Uppenberg et al., 1994). In orthorhombic form (1TCA), where a single monomer is present in the asymmetric unit, the hydrophobic surface is packed against a neighboring molecule, with the side chain of Leu199 from a symmetry-related molecule pointing into the active center and therefore partly responsible for stabilization of the opening of active site channel.

In the hexagonal form (4ZV7), where also a single monomer is present in the asymmetric unit, the active site of a monomer is packed towards the active site of a symmetry-related molecule. Such packing of the symmetrical pairs extends along the crystallographic $c$-axis.There is no sign of any dimerization between these pairs. Instead, the active sites which point towards each other in the symmetrical neighbors, create a solvent-accessible channel, which extends along the entire planes, which are parallel to the plane formed by the unit-cell edges $a$ and $b$. Such packing of all molecules in the crystal makes the active centers very well accessible for the ligands.

\section{Acknowledgements}

Financial support by the Polish National Science Center, grant No. DEC-2012/05/B/ST4/00075, is gratefully acknowledged. The authors used BL14.1 beamline operated by the Helmholtz-Zentrum Berlin (HZB) at the
BESSY II electron storage ring (Berlin-Adlershof, Germany) for diffraction tests and collection of the initial data sets from the lipase microcrystals. The coordinates and structure factors of the hexagonal form of CAL$\mathrm{B}$ apoenzyme have been deposited in the Protein Data Bank (PDB), as entry 4ZV7.

\section{REFERENCES}

Alatorre-Santamaria S, Gotor-Fernandez V, Gotor V (2011) Chemoenzymatic synthesis of optically active cis- and trans-2- $(1 \mathrm{H}$-imidazol1-yl)cycloalkanamines. Eur J Org Chem 6: 1057-1063. doi: 10.1002/ ejoc. 201001299.

Andualema B, Gessesse A (2012) Microbial lipases and their industrial applications: review. Biotechnology 11: 100-118. doi: 10.3923/biotech.2012.100.118.

Bornscheuer UT, Kazlauskas RJ (1999) Hydrolases in organic synthesis: regio- and stereoselective biotransformations. Wiley-VCH, Weinheim, Germany. doi: 10.1002/3527607544.ch7.

Branneby C, Carlqvist P, Hult K, Brinck T, Berglund P (2004) Aldol additions with mutant lipase: analysis by experiments and theoretical calculations. J Mol Catal B Ensym 31: 123-128. doi: 10.1016/j. molcatb.2004.08.005.

Baldessari A (2012) Lipases as catalysts in synthesis of fine chemicals. Meth Mol Biol 861: 445-456. doi: 10.1007/978-1-61779-600-5_25.

Carboni-Oerlemans C, Dominguez de Maria P, Tuin B, Bargeman G, van der Meer A, van Gemert R (2006) Hydrolase-catalysed synthesis of peroxycarboxylic acids: biocatalytic promiscuity for practical applications. J Biotechnol 126: 140-151. doi:10.1016/j.jbiotec.2006.04.008.

Carlqvist P, Eklund R, Hult K, Brinck T (2003) Rational design of a lipase to accommodate catalysis of Baeyer-Villiger oxidation with hydrogen peroxide. J Mol Model 9: 164-171. DOI 10.1007/s00894003-0128-y.

Carlqvist P, Svedendahl M, Branneby C, Hult K, Brinck T, Berglund P (2005) Exploring the active-site of a rationally redesigned lipase for catalysis of Michael-type additions. ChemBioChem 6: 331-336. doi: 10.1002/cbic.200400213.

Colton IJ, Yin DL, Grochulski P, Kazlauskas RJ (2011) Molecular basis of chiral acid recognition by Candida rugosa lipase: X-ray structure of transition state analog and modeling of the hydrolysis of methyl 2-methoxy-2-phenylacetate. Adv Synth Catal 353: 2529-2544. doi: 10.1002/adsc.201100459.

Cygler M, Grochulski P, Kazlauskas RJ, Schrag JD, Bouthillier F, Rubin B, Serreqi AN, Gupta AK (1994) A structural basis for the chiral preferences of lipases. J Am Chem Soc 116: 3180-3186. doi: $10.1021 / \mathrm{ja} 00087 \mathrm{a} 002$.

Deska J, Ochoa CD, Backvall JE (2010) Chemoenzymatic dynamic kinetic resolution of axially chiral allenes. Chem Eur J 16: 4447-4451. doi: 10.1002/chem.201000301.

Emsley P, Lohkamp B, Scott WG, Cowtan K (2010) Features and development of Coot. Acta Cryst D66: 486-501. doi: 10.1107/ S0907444910007493.

Evans PR, Murshudov GN (2013) How good are my data and what is the resolution? Acta Cryst D69: 1204-1214. doi:10.1107/ S0907444913000061.

Frykman H, Ohrner N, Norin T, Hult K (1993) S-Ethyl thiooctanoate as acyl donor in lipase-catalyzed resolution of secondary alcohols. Tetrabedron Lett 34: 1367-1370. doi: 10.1016/S0040-4039(00)91797-0.

Grochulski P, Li Y, Schrag JD, Bouthillier F, Smith P, Harrison D, Rubin B, Cygler M (1993) Insights into interfacial activation from an open structure of Candida rugosa lipase. J Biol Chem 268: 1284312847. PMID: 8509417.

Grochulski P, Bouthillier F, Kazlauskas RJ, Serreqi AN, Schrag JD, Ziomek E, Cygler M (1994) Analogs of reaction intermediates identify a unique substrate binding site in Candida rugosa lipase. Biochemistry 33: 3494-3500. doi: 10.1021/bi00178a005.

Grochulski P, Li Y, Schrag JD, Cvgler M (1994) Two conformational states of Candida rugosa lipase. Protein Sci 3: 82-91. doi: 10.1002/ pro. 5560030111 .

Hult K, Berglund P (2007) Enzyme promiscuity: mechanism and applications. Trends Biotechnol 25: 231-238. doi: 10.1016/j. tibtech.2007.03.002.

Kaczmarczyk S, Kwiatkowska M, Madalińska L, Barbachowska A, Rachwalski M, Błaszczyk J, Sieroń L, Kiełbasiński P (2011) Enzymatic synthesis of enantiopure precursors of chiral bidentate and tridentate phosphorus catalysts. Adv Synth Catal 353: 2446-2454. doi: 10.1002/adsc.201100280.

Kiełbasiński P, Żurawiński R, Albrycht M, Mikołajczyk M (2003) The first enzymatic desymmetrizations of prochiral phosphine oxides. Tetrabedron Asymmetry 14: 3379-3384. doi: 10.1016/j.tetasy.2003.08.003. 
Kiełbasiński P, Mikołajczyk M (2007) Chiral heteroatom-containing compounds. In Future directions in biocatalysis. Matsuda T, ed, pp 159203. Elsevier. doi: 10.1016/B978-044453059-2/50009-1.

Kim KK, Song HK, Shin DH, Hwang KY, Suh SW (1997) The crystal structure of a triacylglycerol lipase from Pseudomonas cepacia reveals a highly open conformation in the absence of a bound inhibitor. Structure 5: 173-185. doi: 10.1016/S0969-2126(97)00177-9.

Kim SK, Lee HH, Park YC, Jeon ST, Son SH, Min WK, Seo JH (2014) Crystal structure of Candida antarctica lipase B with anion-tag. The Protein Data Bank (PDB) entry 3W9B. doi: 10.2210/pdb3w9b/ pdb.

Kirk O, Christensen MW (2002) Lipases from Candida antarctica: unique biocatalysts from a unique origin. Org Prog Res Dev 6: 446-451. doi: 10.1021/op0200165.

Ko SB, Baburaj B, Kim MJ, Park J (2007) Air-stable racemization catalysts for the dynamic kinetic resolution of secondary alcohols. $J$ Org Chem 72: 6860-6864. doi: 10.1021/jo071065o.

Krasiński G, Cypryk M, Kwiatkowska M, Mikołajczyk M, Kiełbasiński P (2012) Molecular modeling of the lipase-catalyzed hydrolysis of acetoxymethyl(i-propoxy) phenylphosphine oxide and its Pborane analogue. J Mol Graph Model 38: 290-297. doi: 10.1016/j. jmgm.2012.09.001.

Kwiatkowska M, Krasiński G, Cypryk M, Cierpiał T, Kiełbasiński P (2011) Lipase-mediated stereoselective transformations of chiral organophosphorus P-boranes revisited: revision of the absolute configuration of alkoxy(hydroxymethyl)phenylphosphine P-boranes. Tet rahedron Asymmetry 22: 1581-1590. doi: 10.1016/j.tetasy.2011.08.024.

Madalińska L, Kwiatkowska M, Cierpiał T, Kiełbasiński P (2012) Investigations on enzyme catalytic promiscuity: the first attempts at a hydrolytic enzyme-promoted conjugate addition of nucleophiles to $\alpha, \beta$-unsaturated sulfinyl acceptors. I Mol Catal B Ensym 81: 25-30. doi: 10.1016/j.molcatb.2012.05.002.

Mancheno JM, Pernas MA, Martinez MJ, Ochoa B, Rua ML, Hermoso JA (2003) Structural insights into the lipase/esterase behavior in the Candida rugosa lipases family: crystal structure of the lipase 2 isoenzyme at $1.97 \AA$ resolution. I Mol Biol 332: 1059-1069. doi: 10.1016/j.jmb.2003.08.005.

McCoy AJ (2007) Solving structures of protein complexes by molecular replacement with Phaser. Acta Cryst D63: 32-41. doi:10.1107/ S0907444906045975.

Murshudov GN, Skubak P, Lebedev AA, Pannu NS, Steiner RA, Nicholls RA, Winn MD, Long F, Vagin AA (2011) REFMAC5 for the refinement of macromolecular crystal structures. Acta Cryst D67: 355-367. doi: 10.1107/S0907444911001314.

Naik S, Basu A, Saikia R, Madan B, Paul P, Chaterjee R, Brask J, Svendsen A (2010) Lipases for use in industrial biocatalysis: specificity of selected structural groups of lipases. J Mol Catal B Ensym 65 18-23. doi: 10.1016/j.molcatb.2010.01.002.

Otto RT, Scheib H, Bornscheuer UT, Pleiss J, Syldatk C, Schmid RD (2000) Substrate specificity of lipase B from Candida antarctica in the synthesis of aryl aliphatic glycolipids. J Mol Catal B Ensym 8: 201 211. doi: 10.1016/S1381-1177(99)00058-2

Paravidino M, Groger H, Hanefeld U (2012) In Enzyme Catalysis in.

Organic Synthesis. Drauz K, Groger H, May O, eds, pp 251-362. WileyVCH, Weinheim, Germany. doi: 10.1002/9783527639861.ch8.

Patterson LD, Miller MJ (2010) Enzymatic deprotection of the cephalosporin 3'-acetoxy group using Candida antarctica lipase B. I Org Chem 75: 1289-1292. doi: 10.1021/jo902406b.

Qian Z, Horton JR, Cheng X, Lutz S (2009) Structural redesign of lipase B from Candida antarctica by circular permutation and incremental truncation. J Mol Biol 393: 191-201. doi: 10.1016/j. jmb.2009.08.008.
Rachwalski M, Kwiatkowska M, Drabowicz J, Kłos M, Wieczorek WM, Szyrej M, Sieroń L, Kiełbasiński P (2008) Enzyme-promoted desymmetrization of bis(2-hydroxymethylphenyl) sulfoxide as a route to tridentate chiral catalysts. Tetrahedron Asymmetry 19: 20962101. doi: 10.1016/j.tetasy.2008.08.017.

Rustoy EM, Sato Y, Nonami H, Erra-Balsells R, Baldessari A (2007) Lipase-catalyzed synthesis and characterization of copolymers from ethyl acrylate as the only monomer starting material. Polymer 48: 1517-1525. doi: 10.1016/j.polymer.2007.01.040.

Santaniello E, Casati S, Ciuffreda P (2006) Lipase-catalyzed deacylation by alcoholysis: a selective, useful transesterification reaction. Curr Org Chem 10: 1095-1123. doi: 10.2174/138527206777698110.

Sharma D, Sharma B, Shukla AK (2011) Biotechnological approach of microbial lipase: a review. Biotechnology 10: 23-40. doi: 10.3923/biotech.2011.23.40.

Sharma UK, Sharma N, Kumar R, Kumar R, Sinha AK (2009) Biocatalytic promiscuity of lipase in chemoselective oxidation of aryl alcohols/acetates: a anique synergism of CAL-B and $\mathrm{Br}$ for the metal-free $\mathrm{H}_{2} \mathrm{O}_{2}$ activation. Org Lett 11: 4846-4848. doi: 10.1021/ ol901917e.

Singh AK, Mukhopadhyay M (2012) Overview of fungal lipase: A review. Appl Biochem Biotechnol 166: 486-520. doi: 10.1007/s12010-0119444-3.

Song X, Qi X, Hao B, Qu Y (2008) Studies of substrate specificities of lipases from different sources. Eur I Litid Sci Technol 110: 10951101. doi: 10.1002/ejlt.200800073.

Svedendahl M, Hult K, Berglund P (2005) Fast carbon-carbon bond formation by a promiscuous lipase. I Am Chem Soc 127: 1798817989. doi: $10.1021 / \mathrm{ja} 056660 \mathrm{r}$.

Uppenberg J, Hansen MT, Patkar S, Jones TA (1994) The sequence, crystal structure determination and refinement of two crystal forms of lipase B from Candida antarctica. Structure 2: 293-308. doi:10.1016/ S0969-2126(00)00031-9.

Uppenberg J, OehrnerN, Norin M, Hult K, Kleywegt GJ, Patkar S, Waagen V, Anthonsen T, Jones TA (1995) Crystallographic and molecular-modeling studies of lipase B from Candida antarctica reveal a stereospecificity pocket for secondary alcohols. Biochemistry 34 : 16838-16851. doi: 10.1021/bi00051a035.

Waagen V, Hollingstaeter I, Partali V, Thorstad O, Anthonsen T (1993) Enzymatic resolution of butanoic esters of 1-phenyl, 1-phenylmethyl, 1-[2-phenylethyl] and 1-[2-phenoxyethyl] ethers of 3-methoxy-1,2-propanediol. Tetrahedron Asymmetry 4: 2265-2274. doi: 10.1016/S0957-4166(00)80077-4.

Winn MD, Ballard CC, Cowtan KD, Dodson EJ, Emsley P, Evans PR, Keegan RM, Krissinel EB, Leslie AGW, McCoy A, McNicholas SJ, Murshudov GN, Pannu NS, Potterton EA, Powell HR, Read RJ, Vagin A, Wilson KS (2011) Overview of the CCP4 suite and current developments. Acta Cryst D67: 235-242. doi: 10.1107/ S0907444910045749.

Wu Q, Liu BK, Lin XF (2010) Enzymatic promiscuity for organic synthesis and cascade process. Curr Org Chem 14: 1966-1988. doi: 10.2174/138527210792927591.

Wu Q, Soni P, Reetz MT (2013) Laboratory evolution of enantiocomplementary Candida antarctica lipase B mutants with broad substrate scope. J Am Chem Soc 135: 1872-1881. doi: 10.1021/ja310455t.

Xie Y, An J, Yang G, Wu G, Zhang Y, Cui L, Feng Y (2014) Enhanced enzyme kinetic stability by increasing rigidity within the active site. J Biol Chem 289: 7994-8006. doi: 10.1074/jbc.M113.536045. 